\title{
Nutritional Counseling for Hypertensive Patients: Have Final-Year Nursing Students Learnt Enough to Be Able to Offer Advice to Such Patients?
}

\author{
Christiana Nsiah-Asamoah, ${ }^{1}$ Jacob Setorglo, ${ }^{2}$ and John Bosco Mie ${ }^{1}$ \\ ${ }^{1}$ Department of Health Sciences Education, University of Cape Coast, Cape Coast, Ghana \\ ${ }^{2}$ Department of Clinical Nutrition and Dietetics, University of Cape Coast, Cape Coast, Ghana \\ Correspondence should be addressed to Christiana Nsiah-Asamoah; cbuxton@ucc.edu.gh
}

Received 25 May 2017; Revised 10 September 2017; Accepted 9 October 2017; Published 31 October 2017

Academic Editor: Stephen D. Helmer

Copyright (c) 2017 Christiana Nsiah-Asamoah et al. This is an open access article distributed under the Creative Commons Attribution License, which permits unrestricted use, distribution, and reproduction in any medium, provided the original work is properly cited.

\begin{abstract}
Background. Although nutrition education for the prevention and management of hypertension is the responsibility of registered dieticians and nutritionist, nurses also play this role particularly because there are few registered dieticians. This study was conducted to assess final-year nursing students' level of knowledge regarding the nutritional prevention and management of hypertension. Methods. A cross-sectional study was conducted to assess their knowledge regarding the dietary management of hypertension. A total of 220 students completed a 21-item nutritional prevention and management of hypertension knowledge test. Results. Students' knowledge about potential modifiable risk factors of hypertension such as excessive salt and alcohol intake was good. Less than half (44.5\%) indicated that they will recommend an increased intake of potassium food sources to hypertensive patients. However, $70.5 \%$ incorrectly indicated that they will advise hypertensive patients to always read nutritional information on food items in order to avoid excessive intake of potassium in their diet. Conclusion. The results of this study indicate that there are some deficits in nursing students' nutritional knowledge for managing hypertension. The findings suggest an urgent need to revise the nursing training curriculum in order to include practical information that can be applied by nursing students, after graduation.
\end{abstract}

\section{Introduction}

Hypertension (BP) is a silent killer; because it is asymptomatic, it manifests itself silently until it develops into adverse cardiovascular diseases such as coronary artery disease and stroke. According to the 2012 health statistics report by World Health Organization (WHO), one in three adults worldwide has raised blood pressure, a condition that results in approximately half of all deaths from stroke and heart disease [1]. It has been projected that the number of hypertensive adults in the world is expected to increase from $25 \%$ to $29 \%$ by 2025 , out of which about $10 \%$ of the population will suffer from secondary hypertension-triggered by a preexisting disease $[2,3]$. It has been predicted that hypertension will be a major cause of death in Sub-Saharan Africa (SSA) by 2020 [4].

Despite the public health concern of this health condition, a systematic review to assess the level of awareness, treatment, and control in Africa revealed low levels of awareness and treatment of hypertension and even lower levels of control [5]. Among the urban poor communities in Accra, Ghana, about a quarter of the young adult population had hypertension; the levels of awareness, treatment, and control were extremely low [6].

As a result of inadequate management and control measures, the prevalence of hypertension in some African countries has increased significantly to more than 30\% [79]. These high prevalence figures have been strongly linked with changes in individual and societal factors such as rapid urbanization, rising levels of obesity, increase in tobacco use, excessive alcohol consumption, reduced physical activity, and adoption of "Western" diets that are high in salt, refined sugar, and unhealthy fats and oils [10-12]. The WHO STEPwise surveys conducted between 2003 and 2009, in 20 African countries, presented information on the determinants for high blood pressure in various settings in Africa. Findings 
presented on the modifiable risk factors for hypertension revealed that a high intake of sodium is common in most African countries where salt is used to preserve food or to make it tastier [13]. In addition, inadequate consumption of fruits and vegetables was reported and this resulted in low potassium intakes. These findings suggest that generally more than $70 \%$ of populations in most African countries are not consuming adequate quantities of fruits and vegetables, which is defined as five or more servings of fruits or vegetables per day. It has been reported that nutritional factors may explain $30-75 \%$ of cases of hypertension, and therefore recent efforts to reduce the prevalence of hypertension have focused on nonpharmacologic strategies, specifically diet [14].

In Ghana, a 10-fold increase in the number of reported new cases of hypertension from 49,087 in 1988 to 505,180 in 2007 has been reported in public health facilities [15]. In Ghana, evidence indicates that many Ghanaians living with hypertension are not aware that they have the condition. The latest Ghana Demographic and Health Survey (GDHS) conducted in 2014 revealed that $63 \%$ and $86 \%$ of adult women and men aged 15 to 49 years, respectively, are not aware that they have high blood pressure [16]. This suggests a high burden of undiagnosed and uncontrolled high blood pressure in the adult Ghanaian population.

Past studies have underscored the fact that the increasing prevalence of hypertension in developing countries is likely to be a result of urbanization, ageing of the population, bad dietary habits, and social stress $[17,18]$.

Within the context of limited resources, in most African countries, the greatest gains in controlling the hypertension epidemic lie in its prevention or at least early detection and adequate control at the primordial level of prevention. An effective control of hypertension demands an improvement in awareness about hypertension among front-line staff such as nurses and an increase in the effectiveness of nonpharmacological interventions such as dietary modifications [19].

It has been reported that, generally, health professionals do not have adequate knowledge for the management of hypertension, which includes lifestyle modifications [20, 21]. In Ghana, there are few registered dieticians, and nurses in most cases play an important role in offering nutritional counseling services to help patients manage most noncommunicable health conditions. However, in Ghana, there is no study that has comprehensively assessed the knowledge levels of final-year nursing students regarding dietary modification strategies that can be recommended to hypertensive patients. Therefore, this study was aimed at assessing the final-year nursing students' levels of knowledge for the dietary management of hypertension.

Study Participants and Informed Consent. The study was comprised of 263 final-year students. Out of the total in the two diploma-awarding nursing colleges, 247 gave their consent to participate in the study and were given a questionnaire to complete; but complete data was finally obtained from 220 nursing students, representing a response rate of $83.7 \%$ of the population of final-year nursing students. Informed consent for inclusion in the study was obtained from all the nursing students. Confidentiality was maintained and anonymity of responses was ensured. Participation was voluntary. Students who agreed to participate in the study were asked to complete the questionnaire in their lecture hall and were not allowed to communicate with other classmates or take the questionnaire out of the lecture hall.

Research Design and Sampling. This was a descriptive crosssectional study. The study population was final-year nursing students who had about two months to complete their diploma programme in two purposively selected nurses training institutions in Ghana.

Research Instrument and Data Collection. Self-administered questionnaires were distributed to all final-year nursing students who gave their consent to participate in the study. Items on the questionnaires were developed based on the Dietary Approaches to Stop Hypertension (DASH) [22] and the World Health Day 2013 Diet, nutrition and hypertension guidelines for the nutritional management of hypertension [23]. Some of the items were also modified versions of questions that were employed in similar studies to assess health practitioners' levels of knowledge regarding recommendations on dietary approaches to prevent and manage hypertension [24, 25]. The questionnaire was given to two registered dieticians for expert advice and comments to improve the construct and content validity of the questionnaire. The questionnaire was then pilot-tested and a reliability coefficient value of 0.72 was determined using Cronbach's alpha coefficient of reliability. Data was collected between 14 and 17 February 2017.

Information sought from the respondents included demographic data, educational background, knowledge about the risk factors, signs, and symptoms, prevention and management of hypertension, and knowledge regarding foods to recommend to hypertensive patients with an emphasis on employing dietary modification strategies.

Data Analysis. The data were analyzed using the Statistical Package for the Social Sciences (SPSS) programme (version 20.0). Descriptive statistics were presented for background information on participants, level of knowledge of the causes, signs, and symptoms of hypertension, and respondents' knowledge of nutrition therapy to manage hypertension. Bar graphs were presented on the knowledge of foods to recommend to hypertensive patients.

Ethical Considerations. Approval for data collection was obtained from the various principals and heads of departments in each participating nurses training institution. The participants were given a cover letter and written information regarding the aim of the study, voluntary participation, and confidentiality of data. The students were informed by the researchers that the study was not being conducted to grade them but to obtain an idea about their nutritional knowledge regarding the management of hypertension for research or academic purposes. In addition, they were told to answer questions that they could and leave out questions that they had no idea about or indicate that by ticking the option "I do not know" as this was included in the answer options. The students were informed that the following steps would be 
TABLE 1: Background information of participants.

\begin{tabular}{lcc}
\hline Variables & $\begin{array}{c}\text { Frequency } \\
(n)\end{array}$ & $\begin{array}{c}\text { Percentage } \\
(\%)\end{array}$ \\
\hline Age (years) & 160 & 72.7 \\
$18-24$ & 50 & 22.8 \\
$25-30$ & 10 & 4.5 \\
$31-35$ & & \\
Sex & 64 & 29.1 \\
Male & 156 & 70.9 \\
Female & & \\
Completed and passed nutrition & & \\
course in NTC & 220 & 100.0 \\
Yes & 0 & 0.0 \\
No & & \\
Number of nutrition courses studied & & \\
in NTC & 220 & 100.0 \\
One & 0 & 0.0 \\
Two & 220 & 100 \\
\hline Total & & \\
\hline
\end{tabular}

taken: (1) questionnaires administered would be anonymous and will not be used to identify any personal information, (2) the questionnaire would be confidentially treated and kept safely under "lock and key" within the University of Cape Coast and the electronic data files will be password-protected, (3) the questionnaires would be stored for at least 5 years after publishing the data in an academic journal and subsequently shredded and discarded, and (4) anonymity would be ensured when the data is published in an academic journal.

A written consent form was attached to the questionnaire for participants consenting to participate to be signed. In addition, returning the questionnaire and written consent form was regarded as informed consent and voluntary participation.

\section{Results}

2.1. Background Information of Study Participants. The background information of the nursing students who participated in the study is presented in Table 1.

The respondents' level of knowledge of the causes, signs, and symptoms of hypertension is summarized in Table 2.

From Table 2, majority (96.4\%) of the respondents knew that regular and excessive intake of alcohol is one of the modifiable risk factors of hypertension. In addition, majority (97.3\%) of the respondents knew that excessive intake of salt will contribute to hypertension development.

As shown in Table 2, a high percentage (76.4\%) demonstrated a high level of knowledge of the signs and symptoms of hypertension. This is an indication that majority of the nursing students will be able to detect early signs and symptoms of hypertension.
Responses given to the questions that assessed students' knowledge about the nutritional management and recommendations for hypertensive patients are summarized in Table 3.

With regard to nutritional recommendations to manage hypertension, higher proportions, $94.1 \%, 89.1 \%$, and $81.8 \%$, indicated that hypertensive patients should be advised to reduce sodium or salt intake, lower saturated fat intake, and reduce body weight, respectively. However, less than half $(44.5 \%)$ indicated that they will recommended an increased intake of potassium from food sources.

Regarding, why it is advisable for hypertensive patients to always read nutritional information on food items, higher proportions of the respondents, $70.5 \%$ and $73.2 \%$, specified that reading of nutritional information enables hypertensive patients to avoid excessive intake of potassium and magnesium, respectively, in their meals. These responses clearly suggest that most of the nursing students had no idea about the importance of increasing intake of food items that have high contents of potassium.

Regarding the ideal recommendation to prevent or manage high blood pressure, with respect to salt restriction, less than half of the respondents $(40.9 \%)$ were able to state that, for primary prevention of hypertension, salt intake has to be reduced to $6 \mathrm{~g} /$ day. Similarly, only $40.0 \%$ were able to indicate that, for secondary prevention of hypertension, salt intake has to be reduced to $4 \mathrm{~g} /$ day.

With respect to the ideal dietary recommendations to manage hypertension, with regard to type of dietary intakes, the majority, $96.4 \%$ and $92.3 \%$, indicated that they will advise hypertension patients to consume diets that are low in salt or sodium and rather increase their intakes of fruits and vegetables, respectively. However, less than half of the respondents (48.2\%) specified that they will recommend diets or food items that contain high levels of potassium.

The study participants were given a number of food items as options that fall under 9 food groups to indicate just one option which they will recommend to a hypertensive patient. The responses given by the students are presented in Figures 1 and 2. Figure 1 depicts proportions of the various food item options that were chosen by the respondents for 5 food groups: meat products, fish/seafood, herbs and spices, fats and oils, and fruits and vegetables.

Figure 2 depicts responses given by the study participants with regard to food options that they will choose for hypertension patients for 4 food groups: milk, yoghurt, breakfast cereals/grains, and root tubers. For the milk food group, the majority (65\%) rightly pointed out that they will recommend skimmed milk and not whole milk to hypertensive patients. However, for breakfast cereals and grains, the majority (62.3\%) wrongly pointed out that they will recommend both rice and oat porridge to hypertension patients, whereas only a few $(10.9 \%)$ correctly indicated that they will recommend oats porridge, a high-fiber-containing cereal, to people suffering from hypertension. With regard to the roots and tubers food group, a high proportion, $48.6 \%$, indicated that they will recommend potatoes to people affected with hypertension. On the other hand, only $31.4 \%$ indicated that they will 
TABLE 2: Level of knowledge of the causes, signs, and symptoms of hypertension.

\begin{tabular}{|c|c|c|}
\hline Variable & Frequency $(n)$ & Percentage (\%) \\
\hline \multicolumn{3}{|c|}{ The term used to describe high blood pressure is known as } \\
\hline Hypertension & 218 & 99.1 \\
\hline Diabetes & 2 & 0.9 \\
\hline \multicolumn{3}{|c|}{ When one's blood pressure is above $120 / 90 \mathrm{~mm} / \mathrm{Hg}$, this may be a sign of } \\
\hline Hypertension & 186 & 84.5 \\
\hline Do not know & 18 & 8.2 \\
\hline Diabetes & 14 & 6.4 \\
\hline Malaria & 2 & 0.9 \\
\hline \multicolumn{3}{|c|}{ Hypertension patients may exhibit signs and symptoms such as } \\
\hline Shortness of breath & 168 & 76.4 \\
\hline Do not know & 26 & 11.8 \\
\hline Paleness & 18 & 8.2 \\
\hline Diarrhea & 8 & 3.6 \\
\hline \multicolumn{3}{|c|}{ Which of the following can hypertension lead to? } \\
\hline Stroke & 180 & 81.8 \\
\hline Diabetes & 30 & 13.6 \\
\hline Gastritis & 4 & 1.8 \\
\hline Do not know & 6 & 2.8 \\
\hline \multicolumn{3}{|c|}{ Which of the following is/are risk factor(s) of hypertension? } \\
\hline Excessive intake of salt & 214 & 97.3 \\
\hline Regular and excessive intakeof alcohol & 212 & 96.4 \\
\hline Intake of high-cholesterol diet & 202 & 92.7 \\
\hline
\end{tabular}

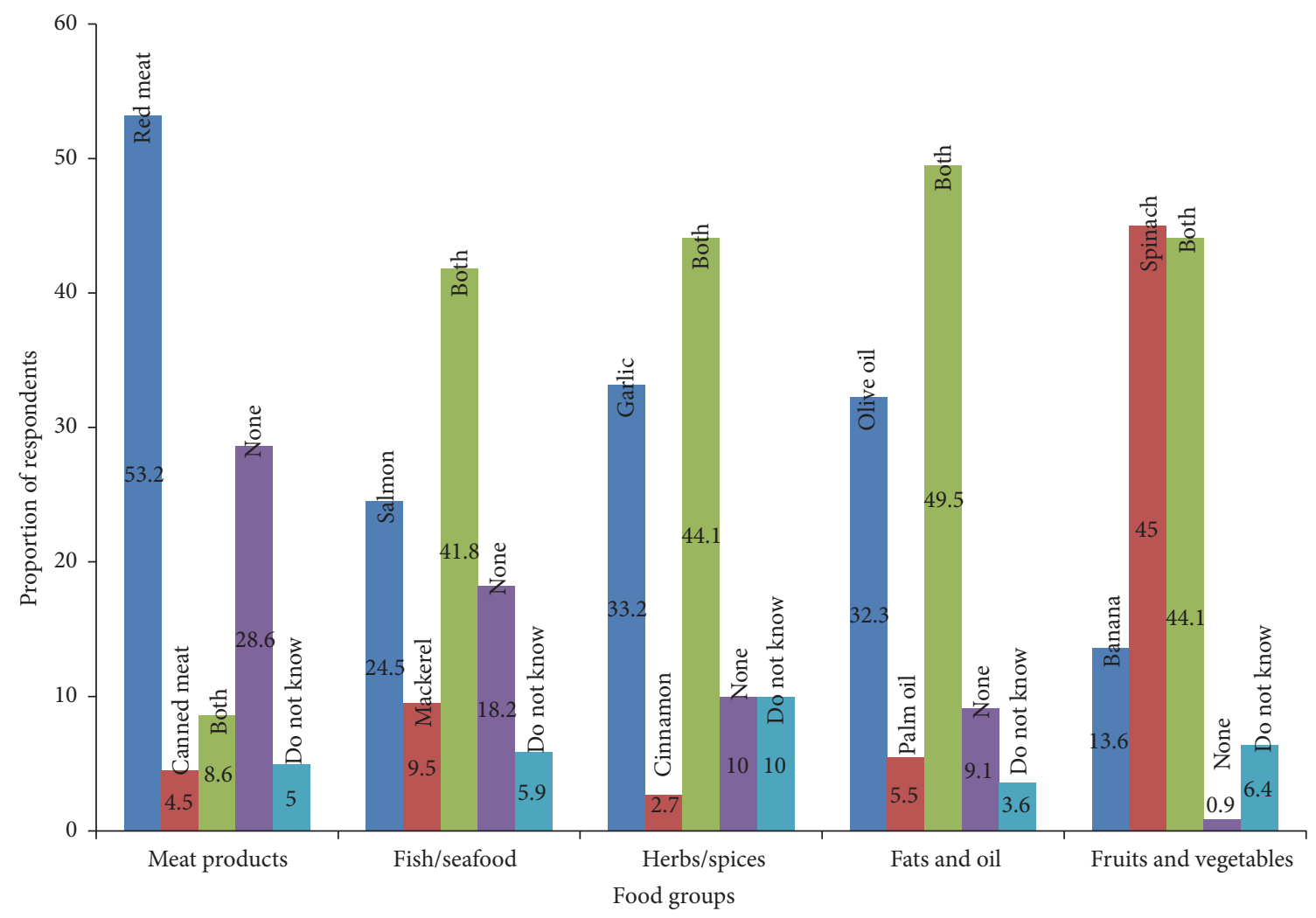

FIGURE 1: Study participants' responses on food items that should be recommended to hypertensive patients. 
TABLE 3: Respondents' knowledge of nutrition therapy to manage hypertension.

\begin{tabular}{|c|c|c|}
\hline Abbreviated questions & Frequency $(n)$ & Percentage (\%) \\
\hline \multicolumn{3}{|l|}{ Nutritional recommendation to manage hypertension } \\
\hline Reduce sodium or salt intake & 207 & 94.1 \\
\hline Reduce weight & 180 & 81.8 \\
\hline Increase potassium intake from food sources & 98 & 44.5 \\
\hline Lower saturated fat intake & 196 & 89.1 \\
\hline Increase magnesium intake from food sources & 82 & 37.3 \\
\hline Advisable for a hypertensive to limit consumption of caffeine & 217 & 98.6 \\
\hline Advisable for a hypertensive to limit consumption of alcoholic beverages & 214 & 97.3 \\
\hline $\begin{array}{l}\text { Advisable for a hypertensive to cultivate the habit of always reading nutritional information on food } \\
\text { items }\end{array}$ & 217 & 98.6 \\
\hline \multicolumn{3}{|l|}{ Reason(s) why it is advisable to always read nutritional information on food items } \\
\hline To avoid excessive intake of sodium/salt in diet & 194 & 88.2 \\
\hline To avoid excessive intake of fats in the diet & 203 & 92.3 \\
\hline To avoid excessive intake of potassium in the diet & 155 & 70.5 \\
\hline \multicolumn{3}{|l|}{$\begin{array}{l}\text { Ideal recommendation to prevent or manage high blood pressure with respect to salt restriction (more } \\
\text { than } 1 \text { answer allowed) }\end{array}$} \\
\hline Reduce salt to $6 \mathrm{~g} /$ day for primary prevention of hypertension & 90 & 40.9 \\
\hline Choose foods with $<400 \mathrm{mg} / 100 \mathrm{~g}$ of salt & 70 & 31.8 \\
\hline Have no idea about recommendation of salt intake to hypertensives & 27 & 12.3 \\
\hline \multicolumn{3}{|l|}{$\begin{array}{l}\text { Ideal recommendation to manage hypertension with respect to type of dietary intakes (more than } 1 \\
\text { answer allowed) }\end{array}$} \\
\hline Consume a diet rich in fruits and vegetables & 203 & 92.3 \\
\hline Consume a diet low in saturated fat and cholesterol & 192 & 87.3 \\
\hline Consume a diet high in potassium & 106 & 48.2 \\
\hline Consume a diet high in fiber & 197 & 89.5 \\
\hline Consume a diet low in salt or sodium & 212 & 96.4 \\
\hline Consume a diet high in nuts such as cashew and almonds & 135 & 61.4 \\
\hline \multicolumn{3}{|l|}{$\begin{array}{l}\text { Ideal recommendation to prevent or manage high blood pressure with respect to fat intake (more than } 1 \\
\text { answer allowed) }\end{array}$} \\
\hline Consume a diet high in unsaturated fat & 112 & 50.9 \\
\hline Consume a diet high in saturated fat & 21 & 9.5 \\
\hline Consume a diet low in unsaturated fat & 53 & 24.1 \\
\hline Consume a diet low in saturated fat & 180 & 81.8 \\
\hline Have no idea about recommendation of fat intakes to hypertensives & 32 & 14.5 \\
\hline
\end{tabular}

recommend both potatoes and cassava, which are both root tuber starchy foods containing high levels of potassium.

\section{Discussion}

This study assessed the final-year nursing students' nutritional knowledge regarding the prevention and management of hypertension. The study specifically focused on the ability of final-year nursing students to provide nutrition counseling on dietary modifications to hypertensive patients.

With regard to nutritional recommendations to manage hypertension, more than $80 \%$ of the respondents indicated that they will advise hypertension clients to reduce sodium or salt intake, lower saturated fat intake, and reduce their body weight, respectively. These are key modifiable risk factors for hypertension development and so it is important that nurse trainees be knowledgeable in this area in order to help reduce the prevalence of hypertension.

Less than half of the respondents indicated that they will advise hypertension patients to increase their intake of potassium-containing food items. Mineral intakes have been found to lower systolic and diastolic blood pressure. Dietary potassium intake has been demonstrated to significantly lower blood pressure (BP) in a dose-responsive manner in both hypertensive and nonhypertensive patients in both observational studies and clinical trials $[14,26]$. Intake of magnesium in particular has been shown to enhance the BPlowering effect of antihypertensive medications [27, 28].

It was encouraging to find that more than $90 \%$ of the respondents indicated that they will advise hypertension patients to reduce intake of alcohol and caffeine and also cultivate the habit of reading nutrition information presented 


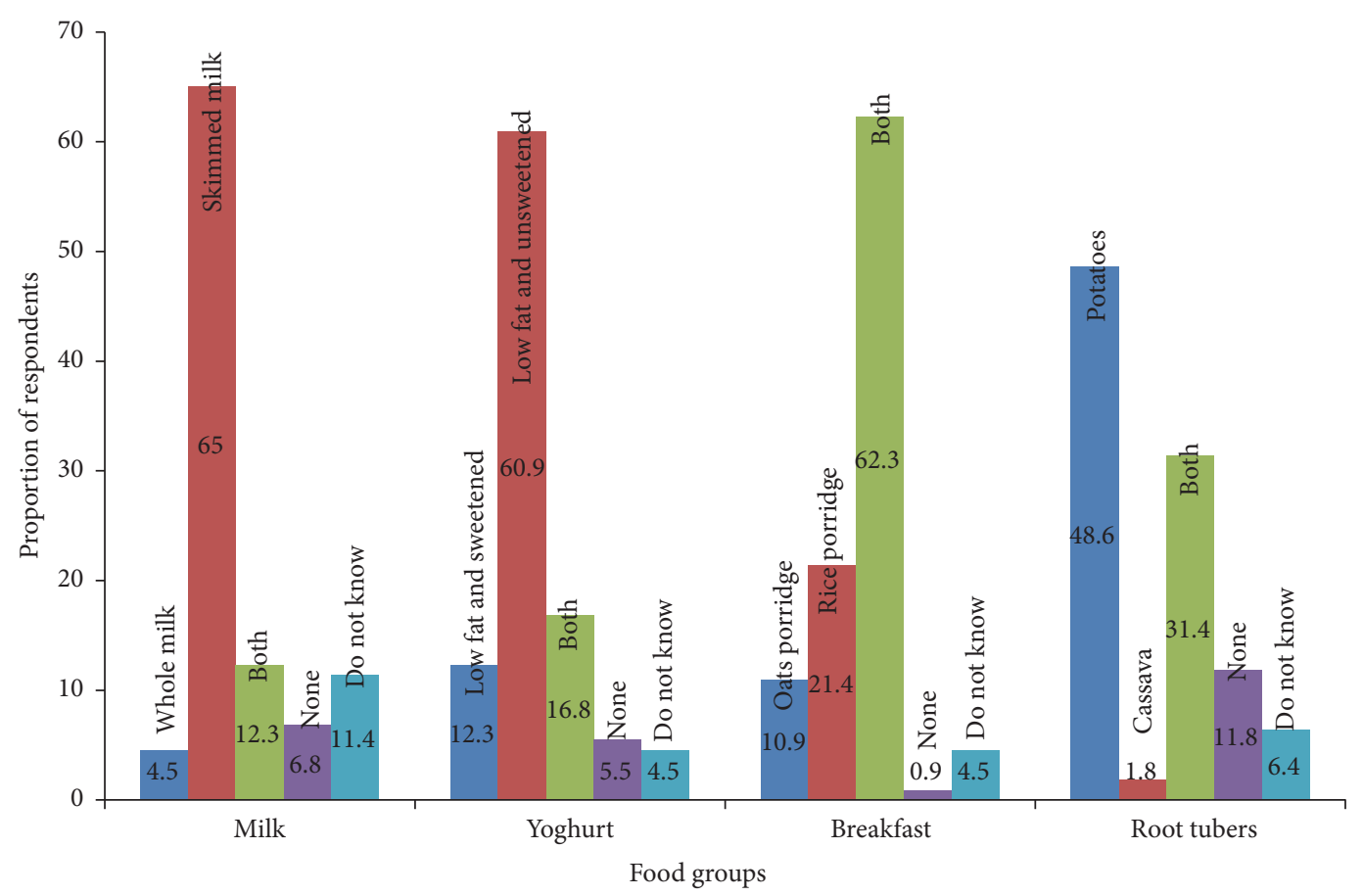

Figure 2: Study participants' responses on food items that should be recommended to hypertensive patients (continued).

on food items. These are risk factors for the occurrence of hypertension, although the evidence for caffeine is mixed. Alcohol intake can lead to endothelial damage of the heart vessels and fat infiltration leading to heart enlargement. In that regard, Nowson and O'Connell (2015) [29] further recommended a maximum of two alcoholic drinks per day for hypertension patients who drink but are making an effort to reduce their alcohol intake.

Respondents indicated that reading nutrition label will enable hypertensives to avoid excessive intake of sodium/salt and fats, respectively, in their diets. High intakes of fat increase the chance of clogging of the lumen of the vessels through fatty plaques formation which can lead to arteriosclerosis. However, a higher proportion as well, $70.5 \%$ and $73.2 \%$, also indicated that reading nutritional information on food labels will enable hypertensive patients to avoid excessive intake of potassium and magnesium, respectively, in their diet. This finding raises great concern regarding nursing students' knowledge of the beneficial role that foods that contain both potassium and magnesium play in the treatment and management of hypertensive conditions. The implication is that these students are likely to naively offer inaccurate nutritional guidelines to patients with hypertension, thereby lowering the progress of their recovery.

Regarding the ideal recommendation on nutrition therapy, the recommendations follow that of DASH. This recommendation, since it is cost-effective, will be easy to follow by patients if the essence is explained to them by nurses. The Dietary Approaches to Stop Hypertension (DASH) diet is an overall eating plan that focuses on eating twice the average daily amount of fruits, vegetables, complex carbohydrates, and low-fat dairy products [22].
Again, the majority, $89.5 \%$ and $96.4 \%$, indicated that they will recommend an increased intake of fiber and a reduced intake of salt/sodium, respectively, to hypertension patients. This finding suggests that the study participants knew the beneficial role of increased fiber which includes lowering of cholesterol levels and reduced salt intakes in lowering blood pressure. In a similar study [30] conducted among Jordanian nurses, the majority also recommended an increased intake of fiber to hypertension patients. The beneficial role of dietary fiber in the prevention and reduction of arterial blood pressure is well presented in literature [31, 32].

With regard to recommendations on fat intake to prevent or manage high blood pressure, the responses of the students are supported by findings of similar studies [29,30]. In a study conducted among nurses in Jordan, a high percentage of the participants believed that patients affected by hypertension should limit their intake of saturated fat (87\%) and trans fat (50\%) [30]. Similarly, in another study among Australian general Practice Registrars, the majority (90\%) indicated that reducing saturated fats was a "highly appropriate" strategy in preventing and managing hypertension conditions [29]. It is important to note that another effect of high intake of fatty foods containing high proportions of long-chain fatty acids is its capability of lowering the absorption of magnesium [33].

Respondents indicated that they will advise hypertensive patients to increase their nuts intake. Indeed, nuts are rich in $\omega-6$ fatty acids which are known to reduce the levels of triglycerides and total cholesterol in the body. Nuts are also very high in potassium [34].

Respondents' knowledge about the importance of potassium in the management of hypertension was low. The 
findings suggest that the nursing students in the present study were not aware of the protective effect of potassium in managing hypertensive conditions. With regard to potassium and its role in preventing or managing hypertension, potassium intake has been found to be inversely related to both diastolic blood pressure and systolic blood pressure in populationbased studies [35]. The $2003 \mathrm{WHO} /$ International Society of Hypertension statement on management of hypertension supported an increased dietary potassium intake, although a threshold was not specified [36].

The findings on the types of food to recommend to a hypertensive patient were worrying. This finding raises concerns about the knowledge levels of the nurses particularly with regard to the negative effect of taking in red meat by hypertensive patients. Hypertensive patients are cautioned against the intake of meat in excessive amounts [37]. In addition, industrially prepared or processed meat products such as canned beef products and salami are often high in sodium and saturated fats [38]. On the other hand, when unprocessed lean meat which is low in saturated fat is consumed, it can be a good source of magnesium. Therefore, since hypertensive patients are generally advised to reduce their fat and salt intake, it will be helpful that they reduce their intake of particularly nonlean meat and processed meat products.

The findings on recommending the intakes of salmon and mackerel suggest that majority of the nursing students were not aware of the beneficial role played by the natural fatty acids such as $\omega-3$ fats found in both salmon and mackerel. These fatty acids, such as $\omega-3$ fats, are extremely beneficial in lowering the risk of hypertension conditions [39].

For herbs and spices, the finding indicates that some of the students knew about the medicinal role of garlic in lowering high blood pressure through its vasodilation properties. Studies have indicated that supplementing one's diet with garlic significantly lowers elevated blood pressure $[40,41]$.

With regard to cinnamon, some studies have confirmed that even short-term use of cinnamon can significantly reduce blood pressure, particularly among those who have comorbidities [42, 43].

For the recommendation of intake of fats and oils, a higher proportion indicated that they will recommend both palm and olive oils to hypertensive patients. Ample evidence in literature indicates that olive oil can be recommended to hypertensive patients because it is rich in heart-healthy monounsaturated fats and phenolic antioxidants $[44,45]$. For palm oil, past studies that were conducted to assess its effect on blood pressure levels were mainly carried out on rats $[46,47]$. Experiments that were conducted on rats suggest that palm oil attenuates the progression of salt-induced hypertension and mortality [46, 47]. These experiments revealed that the effect of palm oil on blood pressure levels was largely dependent on whether it was heated or not. For example, the study of Leong et al. (2008) [47] showed that fresh palm oil has no deleterious effects on blood pressure and cardiac tissue, but prolonged consumption of repeatedly heated palm oil may result in an increase in blood pressure level with necrosis of cardiac tissue. While admitting that more research is needed to verify and substantiate findings presented in these past studies that were mainly conducted on rats, it can be inferred that the manner in which palm oil is treated before consumption may determine its effects on blood pressure levels.

In the food group of fruits and vegetables, only $44.1 \%$ were able to correctly indicate that they will recommend both banana and spinach to hypertensive patients. Spinach is a green leafy vegetable for fighting against high blood pressure, mainly because of its high magnesium content, which helps to lower and maintain blood pressure as has been discussed. Some specialists in the field of endocrinology and physiology found out that consuming bananas, sweet potatoes, and spinach on a daily basis could help reverse the deadly condition of hypertension [48].

However, for breakfast cereals and grains, the finding gives an indication that the nursing students' levels of knowledge about the role that oats can play in reducing blood pressure levels are very inadequate. Whole-grain or highfiber breakfast cereals such as oatmeal are protective because of their soluble fiber content $[49,50]$. Oats are also high in potassium, which is important for maintaining healthy blood pressure as has been discussed in the text.

\section{Conclusions}

Findings from the study reveal that most of the final-year nursing students have adequate knowledge of the risk factors, signs, and symptoms and other medical conditions that hypertension can lead to when not properly managed. The findings also demonstrate that, with regard to prevention and management of hypertension using nutritional interventions, a higher proportion (more than $80 \%$ ) indicated that hypertension patients should be advised to reduce sodium or salt intake, lower saturated fat intake, and reduce body weight. It is also encouraging to find that more than $90 \%$ of the respondents indicated that they will advise hypertensive patients to limit their consumption of caffeinated beverages and alcoholic beverages.

However, findings from this study generally highlight suboptimal levels of nutritional knowledge, particularly pertaining to the role played by food sources of potassium, unsaturated fatty acids, and soluble fiber in the management of hypertensive conditions. In addition, majority of the nursing students did not know the medicinal role played by herbs and spices such as cinnamon and garlic in lowering high blood pressures.

Findings from this study also suggest that the management of chronic medical conditions such as hypertension using nutritional therapy might have been overlooked or given less attention in the Ghanaian nursing curricula and that specific clinical nutrition courses should be introduced to these curricula. This is particularly important to nurses, since they are in a better position to inform and educate hypertensive patients and even their relatives or individuals who provide care and support through dietary modifications to help manage the condition. 


\section{Additional Points}

Data Confidentiality and Consent to Participate. Data were collected using an anonymous self-administrated questionnaire. All respondents provided informed consent and were given assurance of confidentiality that the information gathered will be used exclusively for research purposes. The participants were given a cover letter and written information regarding the aim of the study, voluntary participation, and confidentiality of data. A written consent form was attached to the questionnaire for participants consenting to participate to be signed before completing the questionnaire.

\section{Disclosure}

This research received no specific grant from any funding agency in the public, commercial, or not-for-profit sectors other than the authors' research allowance received from the government annually.

\section{Conflicts of Interest}

All authors declare that they have no conflicts of interest.

\section{Authors' Contributions}

Christiana Nsiah-Asamoah conceived the idea of the study, contributed to the study design, assisted with developing the survey instruments, wrote the draft manuscript, and contributed to the final version of manuscript. Jacob Setorglo contributed to the study design, assisted with developing the survey instruments, and contributed to the draft and final version of the manuscript. John Bosco Mie contributed to the study design, assisted with developing the survey instruments, collected and analyzed the data, and contributed to the final version of the manuscript. All the authors read and approved the final manuscript.

\section{Acknowledgments}

The authors would like to acknowledge the time and effort of all the final-year nursing students for their participation in the survey and would also like to thank tutors for their great help and support with the data collection.

\section{References}

[1] World Health Organization, New Data Highlight Increases in Hypertension, Diabetes Incidence, World Health Organization, 2012.

[2] E. Kebede Gudina, Y. Michael, and S. Assegid, "Prevalence of hypertension and its risk factors in southwest Ethiopia: A hospital-based cross-sectional survey," Integrated Blood Pressure Control, vol. 6, pp. 111-117, 2013.

[3] M. U. Khan, S. Shah, and T. Hameed, "Barriers to and determinants of medication adherence among hypertensive patients attended National Health Service Hospital, Sunderland," Journal of Pharmacy and Bioallied Sciences, vol. 6, no. 2, pp. 104-108, 2014.
[4] J. Iwelunmor, S. Blackstone, J. Gyamfi et al., "A concept mapping study of physicians' perceptions of factors influencing management and control of hypertension in Sub-Saharan Africa," International Journal of Hypertension, vol. 2015, Article ID 412804, 9 pages, 2015.

[5] J. Kayima, R. K. Wanyenze, A. Katamba, E. Leontsini, and F. Nuwaha, "Hypertension awareness, treatment and control in Africa: a systematic review," BMC Cardiovascular Disorders, vol. 13, article 54, 2013.

[6] R. B. Awuah, J. K. Anarfi, C. Agyemang, G. Ogedegbe, and A. De-Graft Aikins, "Prevalence, awareness, treatment and control of hypertension in urban poor communities in Accra, Ghana," Journal of Hypertension, vol. 32, no. 6, pp. 1203-1210, 2014.

[7] K. Z. Gebreselassie and M. Padyab, "Epidemiology of hypertension stages in two countries in sub-Sahara Africa: Factors associated with hypertension stages," International Journal of Hypertension, vol. 2015, Article ID 959256, 12 pages, 2015.

[8] S. T. Ntuli, E. Maimela, M. Alberts, S. Choma, and S. Dikotope, "Prevalence and associated risk factors of hypertension amongst adults in a rural community of Limpopo Province, South Africa," African Journal of Primary Health Care and Family Medicine, vol. 7, no. 1, article 847, 2015.

[9] F. Ataklte, S. Erqou, S. Kaptoge, B. Taye, J. B. Echouffo-Tcheugui, and A. P. Kengne, "Burden of undiagnosed hypertension in sub-saharan africa: a systematic review and meta-analysis," Hypertension, vol. 65, no. 2, pp. 291-298, 2015.

[10] K. B. Tibazarwa and A. A. Damasceno, "Hypertension in developing countries," Canadian Journal of Cardiology, vol. 30, no. 5, pp. 527-533, 2014.

[11] S. van de Vijver, H. Akinyi, S. Oti et al., "Status report on hypertension in Africa-consultative review for the 6th Session of the African Union Conference of Ministers of Health on NCD's," The Pan African Medical Journal, vol. 16, article 38, 2013.

[12] J. J. E. Koopman, D. Van Bodegom, K. G. M. Beenakker, J. W. Jukema, and R. G. J. Westendorp, "Hypertension in developing countries," The Lancet, vol. 380, no. 9852, pp. 1471-1472, 2012.

[13] F. P. Cappuccio, S. M. Kerry, F. B. Micah, J. Plange-Rhule, and J. B. Eastwood, "A community programme to reduce salt intake and blood pressure in Ghana," BMC Public Health, vol. 6, article 13, pp. 1-11, 2006.

[14] L. A. Bazzano, T. Green, T. N. Harrison, and K. Reynolds, "Dietary approaches to prevent hypertension," Current Hypertension Reports, vol. 15, no. 6, pp. 694-702, 2013.

[15] Ghana Statistical Service (GSS), Ghana Health Service (GHS), and ICF Macro, Ghana Demographic and Health Survey 2008, GSS, GHS, and ICF Macro, Accra, Ghana, 2009.

[16] Ghana Statistical Service (GSS), Ghana Health Service (GHS), and ICF International, Ghana Demographic and Health Survey 2014, GSS, GHS, and ICF International, Rockville, Md, USA, 2015.

[17] J. Iwelunmor, C. O. Airhihenbuwa, R. Cooper et al., "Prevalence, determinants and systems-thinking approaches to optimal hypertension control in West Africa," Globalization and Health, vol. 10, no. 1, article 42, 2014.

[18] P. Duboz, E. MacIa, N. Chapuis-Lucciani, G. Boëtsch, and L. Gueye, "Migration and hypertension in Dakar, Senegal," American Journal of Physical Anthropology, vol. 149, no. 2, pp. 250-258, 2012.

[19] S. van de Vijver, S. Oti, J. Addo, A. de Graft-Aikins, and C. Agyemang, "Review of community-based interventions for 
prevention of cardiovascular diseases in low- and middleincome countries," Ethnicity \& Health, vol. 17, no. 6, pp. 651-676, 2012.

[20] H. Boene, M. Vidler, O. Augusto et al., "Community health worker knowledge and management of pre-eclampsia in southern Mozambique," Reproductive Health, vol. 13, p. 105, 2016.

[21] A. M. Jingi and J. J. A. N. Noubiap, "Cardiovascular risk factors awareness and prevalence among primary care physicians: an insight from the West region Awareness Initiative Survey to fight cardiovascular disease (WAIT-CVD) in Cameroon," BMC Research Notes, vol. 8, p. 762, 2015.

[22] J. Chatham, The DASH Diet Health Plan: Low-Sodium, Low-Fat Recipes to Promote Weight Loss, Lower Blood Pressure and Help Prevent Diabetes, Callisto Media Inc, 2012.

[23] World Health Organization (WHO), A Global Brief on Hypertension: Silent Killer, Global Public Health Crisis, 2013, http://www.thehealthwell.info/node/466541.

[24] A. Parker, B. Nagar, G. Thomas, M. Badri, and N. B. A. Ntusi, "Health practitioners' state of knowledge and challenges to effective management of hypertension at primary level," Cardiovascular Journal of Africa, vol. 22, no. 4, pp. 186-190, 2011.

[25] K. A. Park, W. I. Cho, K. J. Song, Y. S. Lee, I. S. Sung, and S. M. Choi-Kwon, "Assessment of nurses' nutritional knowledge regarding therapeutic diet regimens," Nurse Education Today, vol. 31, no. 2, pp. 192-197, 2011.

[26] M. S. Stone, L. Martyn, and C. M. Weaver, "Potassium intake, bioavailability, hypertension, and glucose control," Nutrients, vol. 8, no. 7, article 444, 2016.

[27] L. Kass, J. Weekes, and L. Carpenter, "Effect of magnesium supplementation on blood pressure: A meta-analysis," European Journal of Clinical Nutrition, vol. 66, no. 4, pp. 411-418, 2012.

[28] X. Zhang, Y. Li, L. C. Del Gobbo et al., "Effects of magnesium supplementation on blood pressure: a meta-analysis of randomized double-blind placebo-controlled trials," Hypertension, vol. 68, no. 2, pp. 324-333, 2016.

[29] C. A. Nowson and S. L. O'Connell, "Nutrition knowledge, attitudes, and confidence of australian general practice registrars," Journal of Biomedical Education, vol. 2015, Article ID 219198, 6 pages, 2015.

[30] N. M. Al-Shwaiyat, A. B. Sinjillawi, A. S. Al-Rethaiaa et al., "Assessment of therapeutic nutritional knowledge of Jordanian nurses," International Journal of Nutrition and Food Sciences, vol. 2, no. 3, pp. 142-148, 2013.

[31] M. Viuda-Martos, M. C. López-Marcos, J. Fernández-López, E. Sendra, J. H. López-Vargas, and J. A. Perez-Álvarez, "Role of fiber in cardiovascular diseases: A review," Comprehensive Reviews in Food Science and Food Safety, vol. 9, no. 2, pp. 240258, 2010.

[32] A. Aleixandre and M. Miguel, "Dietary fiber and blood pressure control," Food \& Function, vol. 7, no. 4, pp. 1864-1871, 2016.

[33] T. Bohn, "Dietary factors influencing magnesium absorption in humans," Current Nutrition and Food Science, vol. 4, no. 1, pp. 53-72, 2008.

[34] R. Segura, C. Javierre, M. A. Lizarraga, and E. Ros, "Other relevant components of nuts: Phytosterols, folate and minerals," British Journal of Nutrition, vol. 96, no. 2, pp. S36-S44, 2006.

[35] H. Nguyen, O. A. Odelola, J. Rangaswami, and A. Amanullah, "A review of nutritional factors in hypertension management," International Journal of Hypertension, vol. 2013, Article ID 698940, 12 pages, 2013.
[36] World Health Organization and International Society of Hypertension Writing Group, "2003 World Health Organization (WHO)/International Society of Hypertension (ISH) statement on management of hypertension," Journal of Hypertension, vol. 21, no. 11, pp. 1983-1992, 2003.

[37] A. Ravera, V. Carubelli, E. Sciatti et al., "Nutrition and cardiovascular disease: Finding the perfect recipe for cardiovascular health," Nutrients, vol. 8, no. 6, article no. 363, 2016.

[38] S. Eilat-Adar, T. Sinai, C. Yosefy, and Y. Henkin, "Nutritional recommendations for cardiovascular disease prevention," Nutrients, vol. 5, no. 9, pp. 3646-3683, 2013.

[39] B. Yang, M. Q. Shi, Z. H. Li, J. J. Yang, and D. Li, "Fish, longchain n-3 PUFA and incidence of elevated blood pressure: a meta-analysis of prospective cohort studies," Nutrients, vol. 8, no. 1, article 58, 2016.

[40] R. Ashraf, R. A. Khan, I. Ashraf, and A. A. Qureshi, "Effects of Allium sativum (Garlic) on systolic and diastolic blood pressure in patients with essential hypertension," Pakistan Journal of Pharmaceutical Sciences, vol. 26, no. 5, pp. 859-863, 2013.

[41] K. Ried, O. R. Frank, and N. P. Stocks, "Aged garlic extract reduces blood pressure in hypertensives: a dose-response trial," European Journal of Clinical Nutrition, vol. 67, no. 1, pp. 64-70, 2013.

[42] R. Akilen, Z. Pimlott, A. Tsiami, and N. Robinson, "Effect of short-term administration of cinnamon on blood pressure in patients with prediabetes and type 2 diabetes," Nutrition Journal , vol. 29, no. 10, pp. 1192-1196, 2013.

[43] J. Chezem, S. Tickle, N. Fernandes, and J. Bolin, "Short-term effect of cinnamon on blood pressure in middle-aged obese adults," Journal of the Academy of Nutrition and Dietetics, vol. 113, no. 9, p. A32, 2013.

[44] M.-I. Covas, V. Konstantinidou, and M. Fitó, "Olive oil and cardiovascular health," Journal of Cardiovascular Pharmacology, vol. 54, no. 6, pp. 477-482, 2009.

[45] S. Terés, G. Barceló-Coblijn, M. Benet et al., "Oleic acid content is responsible for the reduction in blood pressure induced by olive oil," Proceedings of the National Acadamy of Sciences of the United States of America, vol. 105, no. 37, pp. 13811-13816, 2008.

[46] C.-M. Boon, M.-H. Ng, Y.-M. Choo, and S.-L. Mok, "Super, red palm and palm oleins improve the blood pressure, heart size, aortic media thickness and lipid profile in spontaneously hypertensive rats," PLoS ONE, vol. 8, no. 2, Article ID e55908, 2013.

[47] X. F. Leong, A. Aishah, U. Nor Aini, S. Das, and K. Jaarin, "Heated palm oil causes rise in blood pressure and cardiac changes in heart muscle in experimental rats," Archives of Medical Research, vol. 39, no. 6, pp. 567-572, 2008.

[48] T. Obayendo, "Banana, spinach and sweet potatoes combo, as natural remedy for hypertension," Pharmanews, vol. 39, no. 2, 2017.

[49] D. Aune, N. Keum, E. Giovannucci et al., "Whole grain consumption and risk of cardiovascular disease, cancer, and all cause and cause specific mortality: Systematic review and doseresponse meta-analysis of prospective studies," BMJ, vol. 353, Article ID i2716, 2016.

[50] G.-C. Chen, X. Tong, J.-Y. Xu et al., "Whole-grain intake and total, cardiovascular, and cancer mortality: A systematic review and meta-analysis of prospective studies," American Journal of Clinical Nutrition, vol. 104, no. 1, pp. 164-172, 2016. 


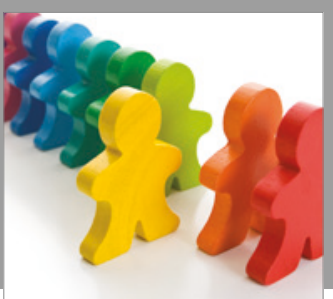

Autism

Research and Treatment
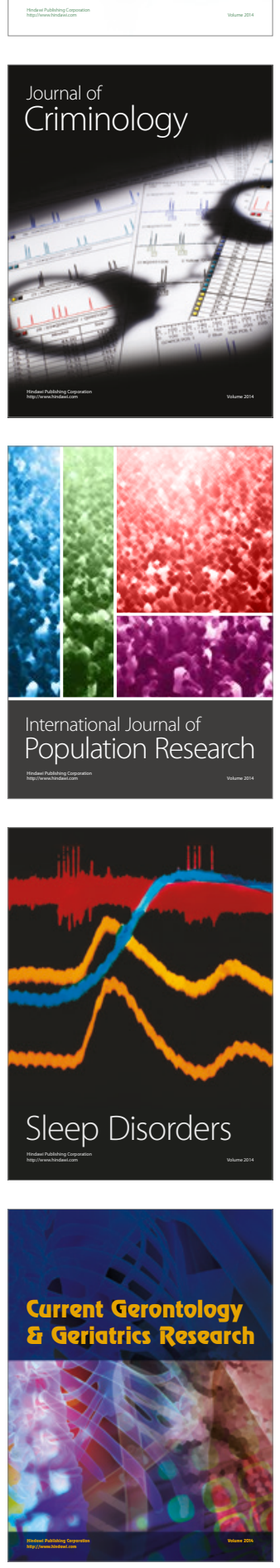

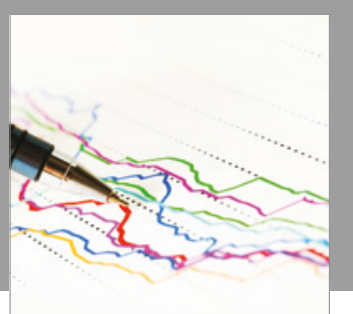

Economics

Research International

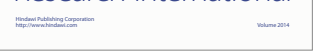

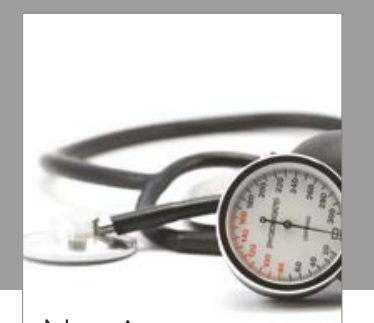

Nursing

Research and Practice

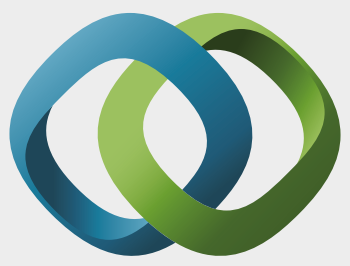

\section{Hindawi}

Submit your manuscripts at

https://www.hindawi.com
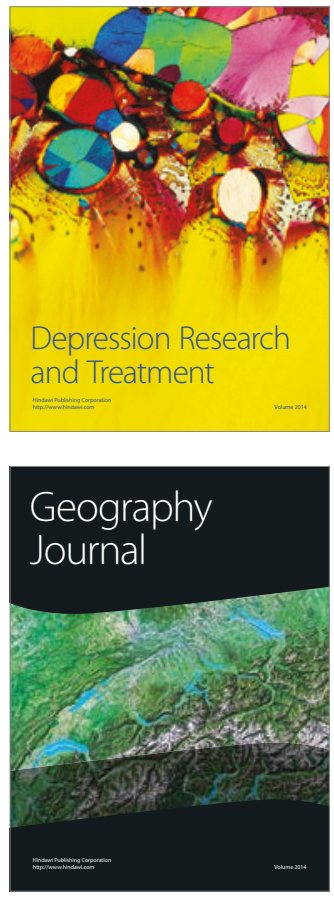
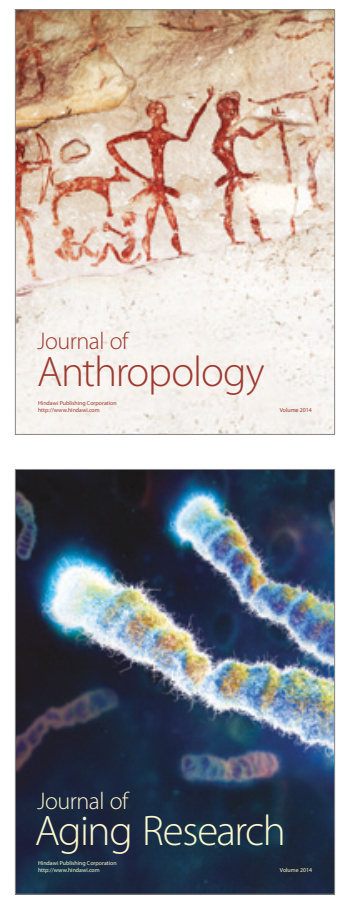
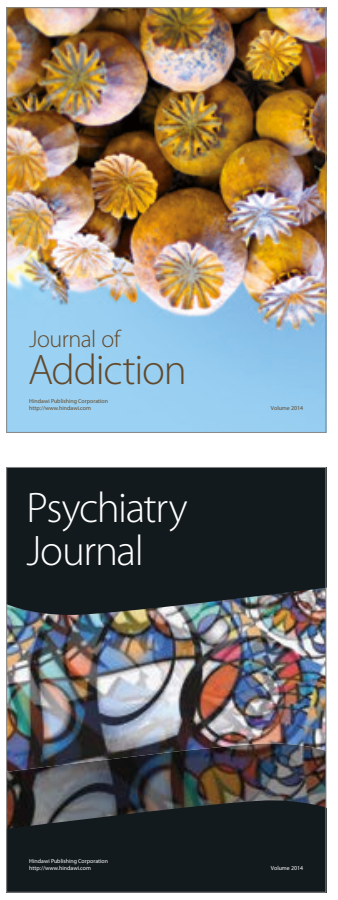

Child Development

Research

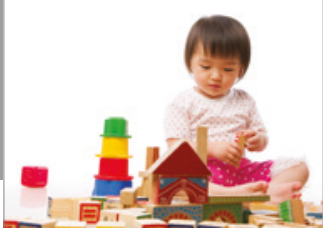

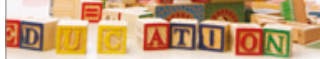
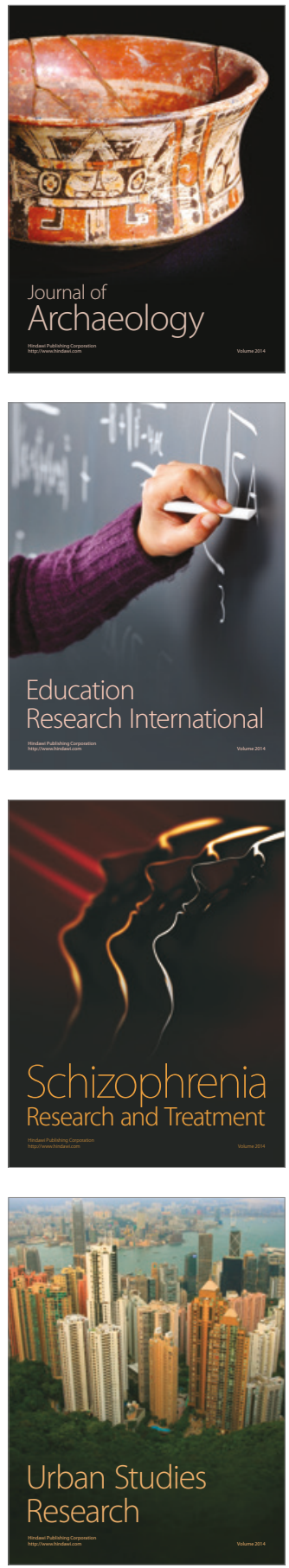